\title{
Invited Address III
}

\section{Putting Information Infrastructure on The Technology Curve}

\author{
David L. Tennenhouse \\ Telemedia, Networks \& Systems Group, \\ Laboratory for Computer Science, \\ Massachusetts Institute of Technology
}

\begin{abstract}
Every day we read about the latest advances in communications technology, from broadband switching to pocket phones. but most of us are still stuck with plain old telephone service. Why has the silicon revolution engendered vibrant growth and rapid change in the computer industry but left the telecommunications infrastructure slower to catch on?

This simple question opens a Pandora's box of inter-twined issues. How do we accommodate the need to continually update the engineering of the network in response to the rapid rate of change in its underlying technologies? How do architectural considerations interact with economic issues such as competition, regulation, and cost structure? Finally, what role should standards and specifications play in the infrastructure engineering process?

This talk will explore these questions from the perspective of computer systems and telecommunications architecture as well as industry economics and structure.
\end{abstract}

